\title{
Optimisation of enzymatic hydrolysis for concentration of squalene in palm fatty acid distillate
}

\begin{abstract}
BACKGROUND: Squalene was concentrated from palm fatty acid distillate (PFAD) in this study using commercial immobilised Candida antarctica lipase (Novozyme 435®). The PFAD was neutralised (NPFAD) using an alkali to liberate the free fatty acids and then hydrolysed at $65 \pm 1{ }^{\circ} \mathrm{C}$. The enzymatic hydrolysis on NPFAD was optimised using response surface methodology (RSM) before being neutralised again to obtain a concentrated squalene fraction. RESULTS: A five-level, three-factor central composite rotatable design was adopted to evaluate the effects of the enzymatic hydrolysis parameters reaction time (4-12 h), water content $(50-70 \% \mathrm{w} / \mathrm{w})$ and enzyme concentration $(1.5-3.5 \% \mathrm{w} / \mathrm{w})$ on the percentage yield of squalene concentration. The optimal reaction parameters for maximum yield of squalene concentration were identified from the respective contour plots. The optimal enzymatic hydrolysis conditions were a reaction time of $7.05 \mathrm{~h}$, a water content of $61.40 \% \mathrm{w} / \mathrm{w}$ and an enzyme concentration of $2.23 \% \mathrm{w} / \mathrm{w}$. CONCLUSION: RSM was used to determine the optimal conditions for enzymatic hydrolysis of NPFAD with C. antarctica lipase for maximum recovery of squalene which could be implemented on an industrial scale.
\end{abstract}

Keyword: enzymatic hydrolysis, palm fatty acid distillate, Candida antarctica, response surface methodology, squalene 